\title{
Bicuspid aortic valve repair in the setting of severe aortic insufficiency
}

\author{
Ziv Beckerman ${ }^{1}$, Michael O. Kayatta ${ }^{1}$, LaRonica McPherson ${ }^{1}$, Jose N. Binongo ${ }^{2}$, Yi Lasanajak ${ }^{2}$, \\ Bradley G. Leshnower ${ }^{1}$, Edward P. Chen ${ }^{1}$ \\ ${ }^{1}$ Division of Cardiothoracic Surgery, Department of Surgery, ${ }^{2}$ Department of Biostatistics and Bioinformatics, Rollins School of Public Health, \\ Emory University School of Medicine, Atlanta, GA, USA \\ Contributions: (I) Conception and design: Z Beckerman, EP Chen; (II) Administrative support: Z Beckerman; (III) Provision of study materials or \\ patients: Z Beckerman, L McPherson; (IV) Collection and assembly of data: Z Beckerman, L McPherson; (V) Data analysis and interpretation: Z \\ Beckerman, JN Binongo, Y Lasanajak; (VI) Manuscript writing: All authors; (VII) Final approval of manuscript: All authors. \\ Correspondence to: Edward P. Chen, MD. Division of Cardiothoracic Surgery, Emory University School of Medicine, 5665 Peachtree Dunwoody \\ Road, Suite 200. Atlanta, GA 30342, USA. Email: epchen@emory.edu.
}

\begin{abstract}
Background: Bicuspid aortic valve (BAV) is a common cardiac anomaly that affects $0.5-2 \%$ of adults. Valve sparing root replacement (VSRR) in bicuspid aortopathy is gaining popularity. We discuss the technical aspects of the procedure as well as the mid- to long-term results of performing VSRR in the setting of a bicuspid valve.
\end{abstract}

Methods: A single institutional database identified 280 patients who underwent VSRR from 2005-2016. Outcomes were analyzed in 60 consecutive patients undergoing a VSRR in the setting of a BAV with aortic regurgitation (AR). Patients were followed prospectively and had annual echocardiograms.

Results: The average age in this series was $42 \pm 11$ years. Moderate or more AR was present in $50 \%$ of patients preoperatively. The incidence of operative death, stroke, and renal failure was $0 \%$. Mean followup was $39 \pm 30$ months. At latest follow-up, $62 \%$ of patients had zero AR and $87 \%$ of patients had $<1+\mathrm{AR}$. At 9 years, freedom from $>2+\mathrm{AR}$ was $97 \%$ and freedom from aortic valve repair (AVR) was $96 \%$.

Conclusions: VSRR can be safely and effectively performed in young patients with bicuspid valve anatomy regardless of degree of pre-operative AR. Valve function is durable and the incidence of valve-related complications is low. VSRR is an attractive and potentially superior option to conventional root replacement in appropriately selected patients with bicuspid aortopathy.

Keywords: Aortic root replacement; aortic valve repair; aortic root; aortic operation; aortic arch

Received: 22 February 2018; Accepted: 03 April 2018; Published: 14 May 2018.

doi: 10.21037 /jovs.2018.04.13

View this article at: http://dx.doi.org/10.21037/jovs.2018.04.13

\section{Introduction}

Bicuspid aortic valve (BAV) is a common cardiac anomaly that affects $0.5-2 \%$ of adults and can present in various phenotypes that includes true bicuspid or three cusps with fusion of two out of three cusps. The clinical course and presentation is variable, and may range from asymptomatic status, isolated aortic regurgitation (AR) or aortic stenosis (AS), infective endocarditis (IE), aortic dilatation (roughly half of patients) or a combination of these (1).

For patients with aortic root dilation with or without aortic valvular pathology, root replacement with a composite valve conduit, as originally described by Bentall et al. (2), has become an established surgical therapy. However, aortic valve replacement with a prosthetic is not free of complications, both mechanical and biological valves are associated with respective clinical issues. Another surgical option, the Ross procedure is associated not only with possible subsequent dilation of the aortic annulus but also with an increased risk for neo-aortic insufficiency and pulmonary homograft insufficiency (3). 
Patients with bicuspid valves often presents with $\mathrm{AR}$ in their 30s and 40s $(4,5)$, while cusp elongation and prolapse lead to worsening AR (6). The development of AR due to aortic dilatation and subsequent need for surgical intervention makes valve sparing root replacement (VSRR) an attractive option. Several groups have shown excellent outcomes with VSRR in these patients (7-10), though the durability of these operations is still unclear.

A recent systematic review by Salcher et al. (11), looked into the clinical literature on outcomes after aortic valve repair in patients with BAV, and found it to be mostly limited to case series and retrospective comparisons of repair techniques within individual centers.

In this paper, we will describe the technical aspects, and pitfalls of BAV repair as well as our own experience and outcomes with VSRR in patients with bicuspid valves.

\section{Methods}

\section{Patient selection and workup}

From January 2005 through December 2016, our institution's database was searched for patients undergoing valve sparing root replacement. We identified 280 consecutive patients, 60 of which had BAVs. Most cases were performed by a single surgeon. Institutional review board approval (IRB00022795) was obtained for the study, and the need for individual patient consent was waived.

Preoperative transesophageal echocardiography (TEE) was routinely performed for all patients. The aortic valve cusps were carefully inspected for any signs of degeneration such as free margin thickening, calcification, and prolapse. The presence and degree of AR was noted, as well as the eccentricity of any regurgitant jets.

Cardiac catheterization or coronary computer tomography (CT) scan was performed depending on the patient's age and risk of coronary artery disease. Pulmonary function testing was performed for patients with smoking history.

\section{Pre-operative preparation}

Preoperative preparation included anesthesiology evaluation and consult. Anesthesia was administered by a dedicated cardiac anesthesiology team. All patients were lined with a large bore peripheral intravenous catheter, brachial arterial line, pulmonary artery catheter, and a double lumen central line catheter. Intraoperative TEE was used to guide the final decision regarding the VSRR procedure.

\section{Equipment preference card}

Standard cannulation technique is recommended, according to the surgeon's preference. Our graft of choice for the David V VSRR is a 3-line Gelweave (Vascutek; Terumo, Ann Arbor, Mich) graft. Typically, 2-0 braided Ethicon sutures with $\mathrm{SH}$ needles are used to anchor the graft (6-8 sutures). For the reimplantation suture line 4-0 TF or 5-0 RB1 Prolene (Ethicon) sutures are used. The coronary buttons anastomoses are performed using 5-0 RB2 Prolene (Ethicon) sutures, and the aortotomy is closed with 4-0 BB Prolene (Ethicon) sutures. In case cusp repair is required, it is performed using a 6-0 GorTex (Gore Medical) or 5-0 RB2 Prolene (Ethicon).

\section{Procedure}

All patients in our series underwent a David V VSRR. Our institution's specific technique has been previously described $(12,13)$, see Figure 1. Cannulation techniques varied depending on the requirement of arch intervention and was previously described (13). After aortic transection, the aortic valve complex is examined for suitability for VSRR. If deemed feasible, we proceed with rood dissection down to the nadir of the aortic annulus, leaving a 4- to 5-mm rim of aortic tissue along the annulus. Coronary buttons are dissected free and mobilized. Decision regarding the graft diameter has been previously described (13). All aortic prostheses used are woven polyester Gelweave (Vascutek; Terumo, Ann Arbor, Mich) grafts. If annular dilation is present, interrupted 3-0 polypropylene sutures are used to plicate the annular end of the graft to the diameter of the valve sizer. Following, 3-0 braided polyester horizontal mattress sutures are passed through the left ventricular outflow tract 1-2 mm below the annulus-nadir and passed through the tailored end of the graft. The graft is then seated (while passing the commissural sutures through the graft first).

Next, the commissural sutures are pulled up vertically and with outward radial traction, for assessment of the optimal height and coaptation. Once decision is made regarding the ideal position of each commissure, the sutures are passed through and tied on the outside of the graft. The valve is then reimplanted into the graft using 3 running 4-0 polypropylene sutures. Next the coronary buttons are reimplanted. The graft may be plicated between the tops of 


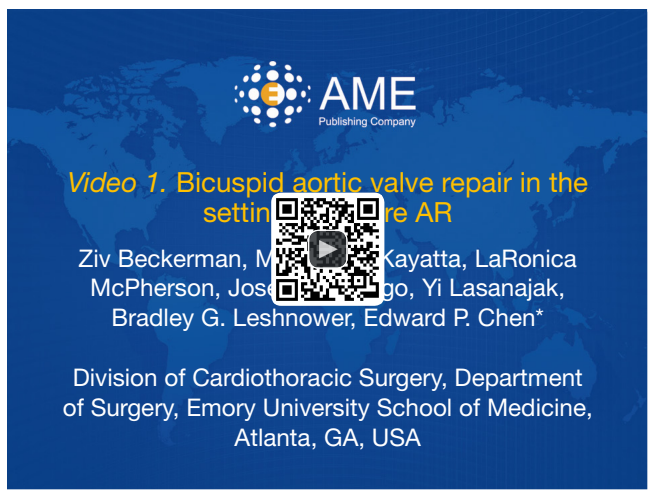

Figure 1 Bicuspid aortic valve repair in the setting of severe AR (14). Available online: http://www.asvide.com/article/view/24745

the commissures with interrupted 4-0 pleating stitches to create a neo-sinotubular junction. Cusp repair procedures are followed if needed. Following, the distal anastomosis is completed.

\section{Post-operative management}

Blood pressure control is aimed at maintaining mean arterial pressure around $80 \mathrm{mmHg}$. Commonly early extubation can be achieved. Typically, a patient would spend 1-2 days in the ICU and an additional 2-4 days in the ward. Our follow-up includes annual echocardiograms. Presence and degree of AR is measured, and LV function and dimensions are also recorded. AR is graded according to a semi-quantitative scale: grade 0 none to trace, grade 1 mild, grade 2 moderate, grade 3 moderate to severe, and grade 4 severe.

\section{Tips, tricks and pitfalls}

BAV differs from tricuspid aortic valve (TAV), the differences between the two necessitate understanding and tailoring of the repair accordingly. The most apparent difference, is that only one coaptation zone is responsible for maintaining adequate valve function. Accordingly, there are also only two relevant commissural posts for the repair. The commissural post associated with the raphe of the conjoined cusp is irrelevant for valve competency.

The initial surgical maneuvers are similar to those undertaken for trileaflet valves, i.e., the aorta is transected, the root dissected out, the abnormal sinus tissue is excised (leaving 4-5 $\mathrm{mm}$ rim of aortic tissue), and the coronary buttons are created.
Next, the valve is assessed as to whether it can be spared or not. Two main maneuvers are utilized: (I) upward traction is placed on the commissural posts of the normal cusp only, and (II) valve coaptation is induced by creation of $\mathrm{LV}$ vacuum ("suction test"), this is typically difficult due to prolapse of the conjoined cusp. The visual inspection of the valve is critical to determine separability, qualities to assess are: (I) cusp degeneration (ideally, the absence of), (II) sclerosis outside the median raphe (ideally, minimal), (III) presence of prolapse/elongated free margin, (IV) cusp restriction (ideally, absence of), and (V) fenestrations (ideally, absence of).

Once the valve is deemed separable, the next critical step is graft sizing. The sizing is based on the free margin length of normal cusp in bicuspid anatomy, minus $4 \mathrm{~mm}$.

Earlier in our experience we favored using the prefabricated Gelweave Valsalva Graft (Vascutek; Terumo, Ann Arbor, MI), however, more recently we prefer a straight tube graft in order allow for more tailoring of the aortic root dimensions. This graft is plicated to narrow slightly at the aortic annulus, and is then lowered into the LVOT with 7-9 interrupted subannular 4-0 braided sutures (unless Sievers type 0).

Once the graft is lowered to the annular level, the commissural posts are suspended. Only relevant commissural posts are those associated with the normal cusp. The commissural post associated with the raphe of the conjoined cusp is irrelevant for valve competency. As a general rule, "Lean" toward 150/210 post angles unless Sievers Type 0.

Following the valve reimplantation inside the graft, any required cusp repair is performed. Cusp repair for correction of aortic insufficiency is primarily focused on the conjoined cusp.

\section{Conclusions}

Our own experience with the David V VSRR for the BAV population includes the outcomes in 60 consecutive patients undergoing a VSRR in the setting of a BAV with AR. The average age of patients in this series was $42 \pm 11$ years, and $80 \%$ were male. The average EF was $54.4 \pm 6.7$. Preoperatively, no AR was found in $25 \%$ of patients, $25 \%$ had mild AR, $23 \%$ moderate AR, and $28 \%$ severe AR. There was only one emergent operation in the series, and $17 \%$ of patients underwent redo-sternotomy. Aortic arch reconstruction requiring circulatory arrest (both hemiarch and total arch) was performed in $70 \%$ of patients. 
Axillary cannulation with antegrade cerebral perfusion was used in most cases, retrograde cerebral perfusion via the SVC was used in $7 \%$. The mean cardiopulmonary bypass time was $229.9 \pm 31.3$ minutes, and the mean duration of circulatory arrest in patients undergoing arch reconstruction was $23.4 \pm 5.7$ minutes.

No patients left the operating room with more than a trace AR. Mean stay in the ICU was $47.6 \pm 37.8$ hours, and hospital length of stay was $6 \pm 2$ days. No patients developed renal failure postoperatively, and there was only one patient $(1.7 \%)$ who had temporary neurologic dysfunction, with no patients suffering permanent dysfunction or stroke.

The average follow-up in this series was $39 \pm 30$ months (range, 1-112 months), and was $98 \%$ complete. At 9 years follow-up, freedom from $>2+\mathrm{AR}$ was $97 \%$ and freedom from AVR was $96 \%$. Freedom from AVR and $>2+$ AR at 9 years was $94 \%$ and $93 \%$, respectively, in patients with preoperative AR $>2+$. Overall, VSRR has been shown to be a reliable procedure associated with low mortality and excellent long-term results.

\section{Comments}

VSRR was initially performed for trileaflet valves with normal cusp anatomy, but with improvements in surgical techniques and postoperative care, the procedure has been expanded to other more complex clinical scenarios. The introduction of valve-sparing operations has proven to be an excellent option for younger patients, allowing for treatment of aortic root pathology while preserving native aortic valve function. VSRR is a particularly attractive option in patients with bicuspid valve anatomy associated with valve insufficiency and aortopathy, as this population is often quite young with an otherwise normal life expectancy.

Our data suggest that despite the complex nature of the operation and the high incidence of needing aortic arch reconstruction with hypothermic circulatory arrest, operative outcomes were excellent. No patient suffered an operative mortality and there was an extremely low incidence of postoperative morbidity. Following the correction of AR, improvements in left ventricular function and remodeling were observed. In longitudinal echo followup, the incidence of recurrent AR or need for AVR was extremely low.

One of the primary advantages of VSRR is the potential reduction in valve-related complications associated with prosthetic replacement. For biological valve replacement, a main concern is the risk of late structural valvular deterioration. Mechanical valves, on the other hand, require a lifelong commitment to anticoagulation. The need for long-term anticoagulation can significantly impact a patient's lifestyle, and even with excellent control there is substantial risk for both bleeding and thrombosis. In young patients, VSRR has been shown to provide improved quality of life over both mechanical and biological valve conduits (15).

The primary concern with VSRR are the risks of performing a more complex, longer operation and the subsequent risk of late reoperation as a result of valve failure and have limited the broader adoption of VSRR in the treatment of aortic root pathology. We discussed above the tips, tricks and pitfalls of VSRR in BAV patients.

One of the advantages of the reimplantation technique is that the entire aortic valve apparatus is supported inside the prosthetic graft used to replace the diseased aortic root segment. Lack of support of the annulus when using the remodeling technique has led to a higher incidence of aortic insufficiency when compared to the remodeling technique, particularly in conditions associated with significant annuloaortic ectasia such as connective tissue disorders and potentially bicuspid valve anatomy (16-18).

In conclusion, use of the David V VSRR appears to be an attractive option for young patients with aortic root pathology and bicuspid valve anatomy. Recurrent AR remains the primary risk of VSRR procedures, and longterm surveillance is therefore mandatory.

\section{Acknowledgements}

This study was supported by Institutional Departmental funding.

\section{Footnote}

Conflicts of Interest: The authors have no conflicts of interest to declare.

Ethical Statement: Institutional review board approval (IRB00022795) was obtained for the study, and the need for individual patient consent was waived.

\section{References}

1. Sievers HH, Sievers HL. Aortopathy in bicuspid aortic valve disease - genes or hemodynamics? or Scylla and Charybdis? Eur J Cardiothorac Surg 2011;39:803-4. 
2. Bentall H, De Bono A. A technique for complete replacement of the ascending aorta. Thorax 1968;23:338-9.

3. David TE, David C, Woo A, et al. The Ross procedure: outcomes at 20 years. J Thorac Cardiovasc Surg 2014;147:85-93

4. Roberts WC. The congenitally bicuspid aortic valve. A study of 85 autopsy cases. Am J Cardiol 1970;26:72-83.

5. Fenoglio JJ Jr, McAllister HA Jr, DeCastro CM, et al. Congenital bicuspid aortic valve after age 20. Am J Cardiol 1977;39:164-9.

6. Robicsek F, Thubrikar MJ, Cook JW, et al. The congenitally bicuspid aortic valve: how does it function? Why does it fail? Ann Thorac Surg 2004;77:177-85.

7. Gaudino M, Lau C, Munjal M, et al. Contemporary outcomes of surgery for aortic root aneurysms: A propensity-matched comparison of valve-sparing and composite valve graft replacement. J Thorac Cardiovasc Surg 2015;150:1120-9.e1.

8. Aicher D, Langer F, Kissinger A, et al. Valve-sparing aortic root replacement in bicuspid aortic valves: a reasonable option? J Thorac Cardiovasc Surg 2004;128:662-8.

9. Pacini D, Settepani F, De Paulis R, et al. Early results of valve-sparing reimplantation procedure using the Valsalva conduit: a multicenter study. Ann Thorac Surg 2006;82:865-71; discussion 871-2.

10. Sareyyupoglu B, Suri RM, Schaff HV, et al. Survival and reoperation risk following bicuspid aortic valve-sparing root replacement. J Heart Valve Dis 2009;18:1-8.

doi: 10.21037 /jovs.2018.04.13

Cite this article as: Beckerman Z, Kayatta MO, McPherson L, Binongo JN, Lasanajak Y, Leshnower BG, Chen EP. Bicuspid aortic valve repair in the setting of severe aortic insufficiency. J Vis Surg 2018;4:101.
11. Salcher M, Naci, Hu, Pender Sarah, et al, Marcus. Bicuspid aortic valve disease: Systematic review and meta-analysis of surgical aortic valve repair. Open Heart 2016;3:e00502.

12. Leshnower BG, Guyton RA, Myung RJ, et al. Expanding the indications for the David V aortic root replacement: early results. J Thorac Cardiovasc Surg 2012;143:879-84.

13. Leshnower BG, Myung RJ, Kilgo PD, et al. Moderate hypothermia and unilateral selective antegrade cerebral perfusion: a contemporary cerebral protection strategy for aortic arch surgery. Ann Thorac Surg 2010;90:547-54.

14. Beckerman Z, Kayatta MO, McPherson L, et al. Bicuspid aortic valve repair in the setting of severe AR. Asvide 2018;5:514. Available online: http://www.asvide.com/article/view/24745

15. Etz CD, Girrbach FF, von Aspern K, et al. Longevity after aortic root replacement: is the mechanically valved conduit really the gold standard for quinquagenarians? Circulation 2013;128:S253-62.

16. Erasmi AW, Sievers HH, Bechtel JF, et al. Remodeling or reimplantation for valve-sparing aortic root surgery? Ann Thorac Surg 2007;83:S752-756; discussion S785-90.

17. Patel ND, Weiss ES, Alejo DE, et al. Aortic root operations for Marfan syndrome: a comparison of the Bentall and valve-sparing procedures. Ann Thorac Surg 2008;85:2003-10; discussion 2010-1.

18. David TE, Feindel CM, Webb GD, et al. Long-term results of aortic valve-sparing operations for aortic root aneurysm. J Thorac Cardiovasc Surg 2006;132:347-54. 